\title{
The comparison of dentin adaptation and sealing ability of gutta-percha/AH Plus, Resilon/Epiphany SE, EndoREZ: an in-vitro study
}

\author{
Mert Gökay Eroğlu ${ }^{1^{*}}$ and Gündüz Şekip Bayırlı \\ ${ }^{1}$ Department of Endodontics, Van Yuzuncu Yil University Faculty of Dentistry, Van, Turkey \\ ${ }^{2}$ Department of Endodontics, Yeditepe University Faculty of Dentistry, Istanbul, Turkey
}

\begin{abstract}
The aim of this study compares three different root canal filling systems (gutta-percha/AH Plus, Resilon/Epiphany SE, EndoREZ) regarding their adaptation root to dentine and their sealing ability at different horizontal sections.

One Hundred extracted single root maxillary incisors were randomly assigned into 3 groups and filled gutta-percha/AH Plus (group GA), Resilon/Epiphany SE (group RE) or EndoREZ root canal filling system (group EZ). All teeth were sectioned horizontally at 1,3 , and $5 \mathrm{~mm}$ from apex. Then teeth layers were examined with stereomicroscope. The ratios of the areas containing core material, sealer and/or voids to the total area were calculated and analyzed statistically.

EndoREZ had significantly more core areas/total areas ratio at $1 \mathrm{~mm}$ compared to the other systems. At $3 \mathrm{~mm}$ level, guttapercha/AH Plus had the lowest core to total area ratio $(\mathrm{p}<0.05)$. At $1 \mathrm{~mm}$ level, EndoREZ had significantly lower sealer+debris+voids ratio than other groups, while gutta-percha/AH Plus had the highest sealer+debris+void areas/total areas at $3 \mathrm{~mm}(\mathrm{p}<0.05)$. When core, sealer, and voids areas were examined within groups, significant differences were found in the ratios of group GA and group RE at different cut sections.

Results are consistent with the previous findings. On the other hand, there are some contradictory results as well. Conflicting findings might result from the differences in the methods of measurement. Moreover, filling materials that are away from the biological cycle may limit in vitro studies. At $1 \mathrm{~mm}$ there are not significantly core areas/total areas group GA and group RE. At 3 and $5 \mathrm{~mm}$ level group GP had significantly lower core areas/total areas
\end{abstract}

Key Words: EndoREZ, gutta-percha/AH Plus, root canal filling, Resilon/Epiphany SE

\section{Introduction}

The root canal filling materials are generally categorized into two groups: solid and semi-solid (1). For an effective root canal filling, solid materials should be used together with the semi-solid ones such as gutta-percha and Resilon (2).

The root canal obturators consist different types of polymers. During gutta-percha placement into root canal, voids can remain between the core material and dentinal wall. Lateral condensation is well known and preffered technique by the clinicians to increase the volume of gutta percha. Many researchers suggest that gutta-percha/sealer technique is not sufficient for a complete hermetic seal (3). The weaknesses of the lateral condensation technique were also reported including insufficient surface adaptation, presence of voids inside the canal filling materials, limited use of spreader, and extreme use of the sealer (4).

In the past thirty years, the development of adhesive techniques brought a revolutionary change in dentistry and the number of products that are manufactured with adesive technology increased on the market. Besides, these materials also became the focus of attention for clinical studies. Resilon/Epiphany, EndoREZ, and MetaSeal are some of the systems using these materials. There is no available root canal filling system, which enables a completely hermetic obturation (5). On the other hand, there are ongoing studies regarding the development of new canal filling materials.

The sealing ability of a root canal filling material between root canal filling and canal wall is, evaluated with adesive ability of its adhesion to the dentinal wall and interfacial adaptation. In this way, hermetic sealing and impermeability of root canal filling materials are controlled as well. In the present study, gutta-percha/AH Plus root canal filling system, Resilon/Epiphany SE and EndoREZ filling system were compared for their adaptation and sealing ability at different horizontal sections. 


\section{Materials and Methods}

100 freshly extracted single-rooted maxillary incisors were used in the current study. Similar sizes of the teeth were selected. Teeth with extensive decay, root resorption, fracture or fissures were eliminated. Subsequently, teeth were seperated into 3 groups $(\mathrm{n}=20)$. All samples were cut decoranated from cemento-enamel junction prior to the shaping procedure. Gutta-percha/AH Plus, EndoREZ, and Resilon/Epiphany SE were used for Group 1, 2 and 3, respectively.

A 10 sized K-type file was inserted into canal apically till the file visible from the foramen. Working length was established with subtracting 1 $\mathrm{mm}$ from this measure. The root canals were shaped with K3 (Sybron Endo, Orange, USA) rotary file system, which was mounted on a hightorque electric motor (speed: $350 \mathrm{rpm}$, contraangle 16:1 reduction).

$10 \mathrm{ml}$ of $5 \% \mathrm{NaOCl}$ (Wizard, Ankara, Turkey) solution were used to irrigate the root canals during the shaping procedure. After irrigation with $\mathrm{NaOCL}$, root canals were irrigated 1 minute with 17\% EDTA (Vista Dental Products, USA). After all, the canals were flushed with the physiological saline solution. In the current study, Resilon+Epiphany (Resilon Research LLC, Madison, CT, USA), gutta-percha (Diadent, Diadent Group International)/AH Plus (Dentsply de Trey, Konstanz-Germany), EndoREZ (Ultradent Products, South Jordan, UT) canal filling systems were used.

All teeth were incubated in an incubator at $37^{\circ} \mathrm{C}$ for one week. When the setting time computed, sections were prepared at the 1,3 , and $5 \mathrm{~mm}$ from the apex.

Each tooth was mounted in an acrylic block. The instrumentation of the blocks were performed with a Buehler-Series Diamond IsoMet Wafering Blade $=15 \mathrm{LC} \quad 1 / 2^{\prime \prime}(12.7 \mathrm{~mm})$ under constant water-cooling. Then sections were examined with a stereomicroscope (Leica DFC320) at 100X magnification.

Finally, (sealer+debris+voids area)/(total area), (core area)/(total area), and (voids area)/(total area) ratios were calculated and the results were analyzed statistically.

Statistical Analysis: National curriculum standards for social studies (NCSS 2007. NCSS, LLC. Kaysville, Utah, USA.) statistical software package was used for the analyses of the results. Firstly, descriptive statistics were performed (mean, standard deviation). Secondly, groups were compared with respect to cut sections $(\mathrm{mm})$ and materials with Kruskal-Wallis test. Lastly, Dunn's Multiple Comparison test was conducted for subgroup comparisons. The significance level for each test was determined at $\mathrm{p}<0.05$.

\section{Results}

The study results revealed that there is a statistically significant difference between (core area)/(total area) ratio of group GA and the core ratios of group $\mathrm{EZ}$ and group $\mathrm{RE}$ at each crosssections $(1,3$, and $5 \mathrm{~mm})(\mathrm{p}<0.05)$. At 1 and 3 $\mathrm{mm}$ cut sections, (core area)/(total area) of group $\mathrm{RE}$ was significantly different from the core ratio of group EZ $(\mathrm{p}<0.05)$.

Group GA and group RE had significantly lower core ratio than group EZ at 1 and $3 \mathrm{~mm}$. Group GA had significantly lower core ratio than group $\mathrm{RE}$ at $3 \mathrm{~mm}$ cut section. Also, group GA had significantly lower core ratio than group EZ and group RE at $5 \mathrm{~mm}$ (Table 1).

Group GA and group RE $(p=0.002, p=0.001)$ showed significantly different core ratios at different horizontal sections $(1,3$, and $5 \mathrm{~mm}$ ). There was no difference statistically group EZ $(\mathrm{p}=0.811)$ (Table 2). Group GA and group RE had significantly different core ratios at different sections $(1,3$, and $5 \mathrm{~mm})$. However, there was no significant difference between the subgroups of

Table 1. Interfactional multi comparisons of the CORE area to the total area

\begin{tabular}{lccccc}
\hline CORE/Total & $\begin{array}{c}1 \mathrm{~mm} \\
\text { Mean } \pm \text { SD }\end{array}$ & $\begin{array}{c}3 \mathrm{~mm} \\
\text { Mean } \pm \text { SD }\end{array}$ & $\begin{array}{c}5 \mathrm{~mm} \\
\text { Mean } \pm \text { SD }\end{array}$ & $\mathrm{KW}$ & $\mathrm{p}$ \\
\hline Gutta-percha/AH Plus & $0.707 \pm 0.108$ & $0.660 \pm 0.138$ & $0.805 \pm 0.094$ & 12.8 & 0.002 \\
EndoREZ & $0.893 \pm 0.097$ & $0.881 \pm 0.087$ & $0.893 \pm 0.051$ & 0.42 & 0.811 \\
Resilon/Epiphany SE & $0.746 \pm 0.158$ & $0.787 \pm 0.116$ & $0.902 \pm 0.052$ & 14.67 & 0.001 \\
$\mathrm{KW}$ & 27.89 & 56.20 & 37.34 & & \\
$\mathrm{p}$ & 0.0001 & 0.0001 & 0.0001 & & \\
\hline
\end{tabular}

SD, Standard deviation; KW, Kruskal-Wallis Test 
the EndoREZ ( $p>0.05)$. Gutta-percha/AH Plus and Resilon/Epiphany SE materials did not have a significant difference between the core ratios of their subgroups at $1 \mathrm{~mm}$ and $3 \mathrm{~mm}$ ( $p>0.05)$; however, they showed significant differences at 5 $\mathrm{mm}$ cut section when compared to the sections at $1 \mathrm{~mm}$ and $3 \mathrm{~mm}(\mathrm{p}<0.05)$ (Table 3$)$.

The (sealer+debris+voids area)/(total area) examination showed that, EndoREZ group had significantly lower ratio when compared to group GA and group $\mathrm{RE}$ at $1 \mathrm{~mm}(\mathrm{p}<0.05)$. There was no statistically significant difference between group GA and group RE ( $p>0.05)$. At $3 \mathrm{~mm}$ level, no significant difference was found between group EZ and group
REgroups, while group GA having the highest sealer+debris+voids ratio than other groups. Similar results were obtained in the sealer+debris +voids ratio at 3 and $5 \mathrm{~mm}$ cut sections (Table 4).

Group GA and group RE showed significant differences in sealer+debris+voids ratio at 1,3 and $5 \mathrm{~mm}(\mathrm{p}<0.05)$, but in group EZ. There was no such differences at different sections $(\mathrm{p}>0.05)$. Group GA and group RE had significantly lower sealer+debris+voids ratio at $5 \mathrm{~mm}$ when compared to $1 \mathrm{~mm}$ and $3 \mathrm{~mm}(\mathrm{p}<0.05)$; however, they did not show a significant difference between subgroups at $1 \mathrm{~mm}$ and $3 \mathrm{~mm}$ cut sections $(\mathrm{p}>0.05)$ (Table 5).

Table 2. Comparison of the rates of the core areas of $1 \mathrm{~mm}, 3 \mathrm{~mm}$ and $5 \mathrm{~mm}$ of the same groups to the total areas in themselves

\begin{tabular}{|c|c|c|c|}
\hline Dunn's Multi Comparison Test ${ }^{1}$ & Gutta-percha/AH Plus & EndoREZ & Resilon/Epiphany SE \\
\hline $1 \mathrm{~mm} / 3 \mathrm{~mm}$ & 0.409 & 0.891 & 0.514 \\
\hline $1 \mathrm{~mm} / 5 \mathrm{~mm}$ & 0.024 & 0.999 & 0.0001 \\
\hline $3 \mathrm{~mm} / 5 \mathrm{~mm}$ & 0.001 & 0.900 & 0.008 \\
\hline
\end{tabular}

${ }^{1}$ The difference between two groups are statistically significant $(\mathrm{p}<0.05)$

Table 3. Rates of the CORE area of $1 \mathrm{~mm}, 3 \mathrm{~mm}$ and $5 \mathrm{~mm}$ of the canal filling substances to the total area in themselves

\begin{tabular}{lccccc}
\hline CORE/Total & $1 \mathrm{~mm}$ & $3 \mathrm{~mm}$ & $5 \mathrm{~mm}$ & $\mathrm{KW}$ & $\mathrm{p}$ \\
\hline Gutta-percha/AH Plus & $0.707 \pm 0.108$ & $0.66 \pm 0.138$ & $0.805 \pm 0.094$ & 12.80 & 0.002 \\
EndoREZ & $0.893 \pm 0.097$ & $0.881 \pm 0.087$ & $0.893 \pm 0.051$ & 0.42 & 0.811 \\
Resilon/Epiphany SE & $0.746 \pm 0.158$ & $0.787 \pm 0.116$ & $0.902 \pm 0.052$ & 14.67 & 0.001 \\
$\mathrm{KW}$ & 27.89 & 56.20 & 37.34 & & \\
$\mathrm{p}$ & 0.0001 & 0.0001 & 0.0001 & & \\
\hline
\end{tabular}

KW, Kruskal-Wallis Test

Table 4. Comparison of the meaningfulness of the rates of the sealer, debris and voids areas in the incisions of $1 \mathrm{~mm}, 3 \mathrm{~mm}$ and $5 \mathrm{~mm}$ to the total incision area in double groups

\begin{tabular}{lccc}
\hline Dunn's Multi Comparison Test $^{1}$ & $1 \mathrm{~mm}$ & $3 \mathrm{~mm}$ & $5 \mathrm{~mm}$ \\
\hline Gutta-Percha AH Plus / EndoREZ & 0.0001 & 0.0001 & 0.004 \\
Gutta-percha+AH Plus / Resilon+ Epiphany SE & 0.860 & 0.001 & 0.001 \\
EndoREZ / Resilon+Epiphany SE & 0.005 & 0.07 & 0.990 \\
\hline
\end{tabular}

${ }^{1}$ The difference between two groups are statistically significant $(p<0.05)$

Table 5. Interfactional multi comparisons of the sealer, debris and voids areas of $1 \mathrm{~mm}, 3 \mathrm{~mm}$ and $5 \mathrm{~mm}$ to the rate of the total area

\begin{tabular}{lccccc}
\hline S.D.V/Total & $1 \mathrm{~mm}$ & $3 \mathrm{~mm}$ & $5 \mathrm{~mm}$ & $\mathrm{KW}$ & $\mathrm{p}$ \\
& Mean \pm SD & Mean \pm SD & Mean \pm SD & & \\
\hline Gutta-percha/AH Plus & $0.293 \pm 0.108$ & $0.340 \pm 0.138$ & $0.195 \pm 0.094$ & 12.8 & 0.002 \\
EndoREZ & $0.107 \pm 0.097$ & $0.119 \pm 0.087$ & $0.108 \pm 0.051$ & 0.42 & 0.811 \\
Resilon/Epiphany SE & $0.253 \pm 0.157$ & $0.206 \pm 0.111$ & $0.096 \pm 0.052$ & 15.27 & 0.0001 \\
KW & 27.94 & 56.95 & 37.46 & & \\
p & 0.0001 & 0.0001 & 0.0001 & & \\
\hline
\end{tabular}

SDV, Sealer Debris Voids; SD, Standard deviation; KW, Kruskal-Wallis Test 
Group GA and group RE had significantly different (sealer+debris+voids area)/(total area) ratios at 1,3 , and $5 \mathrm{~mm}$ cut sections ( $\mathrm{p}=0.002$; $\mathrm{p}=0.001)$. However, this significant difference was not found for the sealer +debris+voids ratio of EndoREZ subgroups $(\mathrm{p}=0.811)$ (Table 6).

Sealer+debris+voids areas/total areas ratio of group GA and group RE were found significantly lower at $5 \mathrm{~mm}$ cut section compared to the sections at 1 and $3 \mathrm{~mm}$ level $(\mathrm{p}=0.024, \mathrm{p}=0.001$; $\mathrm{p}=0.01, \mathrm{p}=0.0001)$. No statistically significant difference was found between the groups at 1 and $3 \mathrm{~mm}(\mathrm{p}>0.05)$ (Table 7).

At 1,3 and $5 \mathrm{~mm}$ cut sections, no statistically significant difference was found between (voids area)/(total area) ratios of the groups. Also, there was no within group differences at different sections $(\mathrm{p}>0.05)$.

\section{Discussion}

Since teeth with wider canal diameters enable the researchers to obturate the root canals with more canal fillings, maxillary incisors were preferred in the current study. In this way, the irregularities in the root canal filling materials at horizontal sections can be easily observed.

The current study aimed to compare the sealing ability of three different canal fillings in apical 1/3 of the root canal system. This region is particularly important for clinical trials in terms of determining the quality of the canal filling material. The prevention of void formation and minimum thickness of the sealing layer are the essentials of long-term success of the root canal treatment. Some researchers take the critical region as 2 and $4 \mathrm{~mm}$ from the apex, (6) but in general, apical 1-5 $\mathrm{mm}$ of the tooth is known as the critical region for root canal treatment.

It is preferred to remove the smear layer for each canal filling technique in the current study. According to the manufacturer's protocol, resinbased sealers such as Resilon, EndoREZ should be irrigated with EDTA solution at the end of the instrumentation. Removing the smear layer provides a better adhesion of the sealer to the dentinal wall (7).

The dye penetration, the bacterial leakage, radioisotope solutions and electrochemical methods are commonly used for evaluation of leakage of the root canal filling material (8-11). In order to avoid from these weaknesses, the most recent and advanced model "Leica DFC320" stereomicroscope was used in the present study.

The root canal fillings at different horizontal sections were examined immediately after the root canal had filled. Therefore, the study is limited in terms of evaluating the long-term effects and other parameters that might have an effect on the sealing ability of the canal fillings in clinical conditions. Some of these parameters are decomposition of the sealer in tissue fluids over time, dimensional changes due to the volume loss, the bond between core and the sealer, the changes

Table 6. Comparisons of the sealer, debris and voids areas of $1 \mathrm{~mm}, 3 \mathrm{~mm}$ and $5 \mathrm{~mm}$ of the same groups to the rates of the total area in themselves

\begin{tabular}{lccc}
\hline Dunn's Multi Comparison Test $^{1}$ & Gutta-percha/AH Plus & EndoREZ & Resilon/Epiphany SE \\
\hline $1 \mathrm{~mm} / 3 \mathrm{~mm}$ & 0.409 & 0.891 & 0.410 \\
$1 \mathrm{~mm} / 5 \mathrm{~mm}$ & 0.024 & 0.999 & 0.0001 \\
$3 \mathrm{~mm} / 5 \mathrm{~mm}$ & 0.001 & 0.900 & 0.01 \\
\hline
\end{tabular}

${ }^{1}$ The difference between two groups are significant $(\mathrm{p}<0.05)$

Table 7. Rates of the sealer, debris and voids area of $1 \mathrm{~mm}, 3 \mathrm{~mm}$ and $5 \mathrm{~mm}$ of the canal filling substances to the total area in themselves

\begin{tabular}{lccccc}
\hline SDV/Total & $1 \mathrm{~mm}$ & $3 \mathrm{~mm}$ & $5 \mathrm{~mm}$ & $\mathrm{KW}$ & $\mathrm{p}$ \\
\hline Gutta-percha/ AH Plus & $0.293 \pm 0.108$ & $0.34 \pm 0.138$ & $0.195 \pm 0.094$ & 12.80 & 0.002 \\
EndoREZ & $0.107 \pm 0.097$ & $0.119 \pm 0.087$ & $0.108 \pm 0.051$ & 0.42 & 0.811 \\
Resilon/Epiphany SE & $0.253 \pm 0.157$ & $0.206 \pm 0.111$ & $0.096 \pm 0.052$ & 15.27 & 0.000 \\
$\mathrm{KW}$ & 27.94 & 56.95 & 37.46 & & \\
$\mathrm{p}$ & 0.0001 & 0.0001 & 0.0001 & & \\
\hline
\end{tabular}

SDV, Sealer Debris Voids; KW, Kruskal-Wallis Test 
in the root canal filling in response to the external forces. Patil et al. (12) found that guttapercha/AH Plus material has significantly higher bond strength than Resilon Epiphany SE material.

In the current study, gutta-percha had significantly lowest core ratio among all groups at every horizontal section. Jacobson et al. (13) compared lateral condensation gutta-percha technique and the thermoplastic gutta-percha techniques in terms of the amount of leakage. They showed that the lateral condensation technique caused significantly more leakage than the "continuous wave of condensation" and "Obtura II" techniques. Although the lateral condensation technique is the most common technique in clinical practice, the results of the present study supported the view that the sealing ability of this system might be problematic.

According to the Toronto Study, which collects and analyses clinical data for 4-6 years, the thermoplastic gutta-percha technique is reported to have $90 \%$ success rate, and the lateral condensation technique is found to have $80 \%$ success rate (14).

Biggs et al. (15) filled the teeth either with Resilon/Epiphany SE or gutta-percha/AH Plus and measured the leakage by using the fluid filtration technique after 24 hours, 1 week, 2 weeks, 30 days, and 90 days following the obturation. In their results, there was no significant difference between the sealing ability of Resilon/Epiphany SE and gutta-percha/AH Plus. Also, there was no effect of time on the amount of leakage. However, current study found that Resilon/Epiphany SE has better sealing ability at 3 and $5 \mathrm{~mm}$ There was no difference between these systems in adaptation to dentin at $1 \mathrm{~mm}$. Since the previous study measured the leakage and did not compare the sealing ability of the systems at different cross-sections, they might fail to find an existing difference between Resilon/Epiphany $\mathrm{SE}$ and gutta-percha/AH Plus, which is found only at 3 and $5 \mathrm{~mm}$ but not at $1 \mathrm{~mm}$. Additionally, in the present study, there was no significant difference between these two group in terms of void formation.

Shemesh et al. (16) compared the leakages along the coronal region of canal fillings of Resilon/Epiphany, and gutta-percha/AH Plus groups. They found that Resilon/Epiphany leaked significantly less than gutta percha/AH Plus group. Correspondingly, Resilon/Epiphany SE showed significantly higher adaptation than guttapercha/AH Plus at 3 and $5 \mathrm{~mm}$ under the current study (no significant difference was found at 1 $\mathrm{mm})$.

Wedding et al. (17) compared microleakage of teeth filled either with gutta-percha and Resilon SE by using a fluid filtration model. They found that Resilon is more resistant to microleakage compared to gutta-percha. In the present study, Resilon/Epiphany SE had the highest core ratio. However, findings are conflicting in terms of void formation.

It was found that, there is no significant difference between AH Plus, EndoREZ and Real Seal groups with respect to leakage. However, all groups allowed the leakage after 20 hours following the obturation (18).

Bodrumlu and Tunga compared the apical leakage of the teeth filled with gutta-percha/AH26, guttapercha/AH Plus and Resilon/Epiphany by lateral condensation (19). They did not find a significant difference between the groups with respect to the sealing ability. They reported that, root canals filled with gutta-percha/AH26 leaked significantly more than the canals filled with the other sealers. The reason of the leakage might be the voids inside the sealer. In that respect, these findings are supported by the present study finding (the significant difference between Resilon/Epiphany SE and gutta-percha/AH Plus in terms of void formation).

Karapinar-Kazandag et al. (20) compared the microleakage of Resilon/Epiphany, EndoREZ, Activ GP, and gutta-percha/AH Plus technique by using the glucose filtration model. They did not found a significant difference between these root canal filling systems. However, in the present study, Resilon/Epiphany SE showed significantly better sealing ability compared to guttapercha/AH Plus.

Monticelli et al. (21) compared the sealing efficacy of warm vertical condensation technique with gutta-percha/AH Plus, single-cone technique with Activ GP, and single-cone technique with GuttaFlow in preventing bacterial leakage. Gutta-percha warm vertical condensation technique showed the highest sealing efficacy in terms of preventing bacterial leakage. However, in the current study, there was no difference between groups in terms of void formation. Differences in methods of measurement may be the reason behind these contradictory findings.

Another study comparing the bond strength and sealing ability of the teeth filled with /guttapercha/AH Plus, EndoREZ and RealSeal systems with the lateral condensation method found no differences between the leakage amount of 
different groups (22). These results show similarity with the present study.

Herbert et al. (23) compared the quality of different sealers (GuttaFlow, Resilon/Epiphany, and EndoREZ) at different horizontal sections, which are at the level of 2 and $4 \mathrm{~mm}$ from the apex. They evaluated the adaptation to dentin and the area of voids by using light microscopy. They found that, Resilon showed the highest sealer adaptation to the root canals. However, there was no significant difference between the groups in terms of void formation. The current study also did not found a difference between these groups.

Pereira et al. (24) compared the sealing ability of dog premolars filled with AH Plus, RoekoSeal and EndoREZ. They found that EndoREZ leaked significantly less than RoekoSeal and they found no statistic difference between $\mathrm{AH}$ Plus and the other sealers. Although the methods of measurements are quite different, the findings of this study is consistent with the current one since we found a significant difference between the voids area of EndoREZ and gutta-percha/AH Plus groups.

Although gutta-percha is still commonly used in clinical practice, many researchers agree upon the view that it has weaknesses (9). In the evaluation of the sealing ability, fluid filtration tests are the still of choice but these tests usually reveal contradictory results $(25,26)$. Therefore the present study used the histological method for a better measurement of the adaptation and sealing ability of the canal fillings.

The most critical region for the root canal treatment is usually accepted as up to $2 \mathrm{~mm}$ from the apex (27). Thus, some researchers prefer to obtain horizontal sections at 2 and $4 \mathrm{~mm}$ from the apical foramen (28).

\section{References}

1. Walton RE, Johnson WT. Obturation. In: Walton RE, Torabinejad M, editors. Principles and Practice of Endodontics. 3rd Edition. Philedelphia: W.B. SaundersCo 2002. p. 239-267.

2. Zielke DR, Brady JM, del Rio CE. Corrosion of silver cones in bone: A scanning electronmicro probe analysis. J Endod 1975; 1: 356-360.

3. Torabinejad M, Ung B, Kettering JD. In vitro bacterial penetration of coronally unsealed endodontically treated teeth. J Endod 1990; 16: 566569.

4. Brayton SM, Davis SR, Goldman M. Gutta-percha root canal fillings. Oral Surg Oral Med Oral Pathol. 1973; 35: 226-231.
5. Clark-Holke D, Drake D, Walton R, Rivera E, Guthmiller JM. Bacterial penetration through canals of endodontically treated teeth in the presence or absence of the smear layer. J Dent 2003; 31: 275-281.

6. Wu MK, Kast'kova A, Wesselink PR. Quality of cold and warm gutta-percha fillings in oval canals in mandibular premolars. Int Endod J 2001; 34: 485491.

7. Leonard JE, Gutmann JL, Guo IY. Apical and coronal seal of roots obturated with a dentine bonding agent and resin. Int Endod J 1996; 29: 7683.

8. Wu MK, Wesselink PR, Boersma J. A 1-year followup study on leakage of four root canal sealers at different thicknesses. Int End 1995; 28: 185-189.

9. Yap A, Stokes AN, Pearson GJ. An in vitro leakage study of a new multi-purposed dental adhesive system. J Oral Rehabil 1995; 23: 302-318.

10. Torabinejad M, Rastegar AF, Kettering JD, Pitt Ford TR. Bacterial leakage of mineral trioxide aggregate as a root-end filling material. J Endod 1995; 21: 109112.

11. Karagöz-Küçükay I. Endodonti'de apikal sızınt1 inceleme yöntemleri. DÜ Diş Hek Fak Derg 1991; 23: 65-79.

12. Patil AS, Dodwad PK, Patil AA. An in vitro comparison of bond strengths of Gutta-percha/AH Plus, Resilon/Epiphany self-etch and EndoREZ obturation system to intra radicular dentin using a push-out test design. J Conserv Dent 2013; 16: 238242.

13. Jacobson HL, Xia T, Baumgartner JC, Marshall JG, Beeler WJ. Microbial leakage evaluation of the continuous wave of condensation. J Endod 2002; 28: 269-271.

14. Farzaneh M, Abitbol S, Lawrence HP, Friedman S; Toronto Study. Treatment outcome in endodonticsthe Toronto Study. Phase II: initial treatment. J Endod 2004; 30: 302-309.

15. Biggs SG, Knowles KI, Ibarrola JL, Pashley DH. An in vitro assessment of the sealing ability of resilon/epiphany using fluid filtration. J Endod 2006; 32: 759-761.

16. Shemesh $H$, van den Bos M, Wu MK, Wesselink PR. Glucose penetration and fluid transport through coronal root structure and filled root canals. Int Endod J 2007; 40: 866-872.

17. Wedding JR, Brown CE, Legan JJ, Moore BK, Vail MM. An in vitro comparison of microleakage between Resilon and gutta-percha with a fluid filtration model. J Endod 2007; 33: 1447-1449.

18. Vasconcelos BC, Bernardes RA, Duarte MA, Bramante CM, Morase If Aniral ceslino of ront canal fillings per

endodontic sealers: a Oral Sci 2011; 19: 324-328.

19. Bodrumlu E, Tunga U. The apical sealing ability of a new root canal filling material. Am J Dent 2007; 20: 295-298. 
20. Karapinar-Kazandağ M, Tanalp J, Bayrak OF, Sunay $H$, Bayirli G. Microleakage of various root filling systems by glucose filtration analysis. Oral Surg Oral Med Oral Pathol Oral Radiol Endod 2010; 109: 96102.

21. Monticelli F, Sadek FT, Schuster GS, et al. Efficacy of two contemporary single-cone filling techniques in preventing bacterial leakage. J Endod 2007; 33: 310313.

22. Mahdi AA, Bolaños-Carmona V, Gonzalez-Lopez S. Bond strength to root dentin and fluid filtration test of AH Plus/gutta-percha, EndoREZ and RealSeal systems. J Appl Oral Sci 2013; 21: 369-375.

23. Herbert J, Bruder M, Braunsteiner J, Altenburger MJ, Wrbas KT. Apical quality and adaptation of Resilon, EndoREZ, and Guttaflow root canal fillings in combination with a noncompaction technique. J Endod 2009; 35: 261-264.
24. PereiraCdaC, De Oliveira EP, Gomes MS, et al. Comparative in vivo analysis of these alingability of three endodontic sealers in dog teeth after post-voids preparation. Aust Endod J 2007; 33: 101-106.

25. Wu MK, De Gee AJ, Wesselink PR, Moorer WR. Fluid transport and bacterial penetration along root canal fillings. Int Endod J 1993; 26: 203-208.

26. Karagenç B, Gençoglu N, Ersoy M, Cansever G, Külekçi G. A comparison of four different microleakage tests for assessment of leakage of root canal fillings. Oral Surg Oral Med Oral Pathol Oral Radiol Endod 2006; 102: 110-113.

27. Hayes SJ, Dummer PM. Late failure of root canal therapy: a diagnostic and treatment planning challenge. Int Endod J 1997; 30: 68-71.

28. Wu MK, van der Sliuis LW, Wesselink PR. A preliminary study of the percentage of gutta-perchafilled area in the apical canal filled with vertically compacted warm gutta-percha. Int Endod J 2002; 35: 527-535. 